\title{
Féeries
}

Études sur le conte merveilleux, XVII $-\mathrm{XIXe}$ siècle

\section{Jeanne Marie Leprince de Beaumont, Contes et} autres écrits

Édition présentée par Barbara Kaltz, Oxford, Voltaire Foundation, 2000, 192 pages.

\section{Anne Defrance}

\section{(2) OpenEdition}

Journals

Édition électronique

URL : http://journals.openedition.org/feeries/86

DOI : $10.4000 /$ feeries.86

ISSN : 1957-7753

Éditeur

UGA Éditions/Université Grenoble Alpes

Édition imprimée

Date de publication : 1 février 2004

ISSN : 1766-2842

Référence électronique

Anne Defrance, "Jeanne Marie Leprince de Beaumont, Contes et autres écrits », Féeries [En ligne], 1 ।

2004, mis en ligne le 29 janvier 2007, consulté le 22 septembre 2020. URL : http://

journals.openedition.org/feeries/86; DOI : https://doi.org/10.4000/feeries.86

Ce document a été généré automatiquement le 22 septembre 2020.

(c) Féeries 


\section{Jeanne Marie Leprince de Beaumont, Contes et autres écrits}

Édition présentée par Barbara Kaltz, Oxford, Voltaire Foundation, 2000, 192 pages.

Anne Defrance

1 L'auteur, maître de conférences à l'université François Rabelais de Tours, offre à un public intéressé par les trois domaines de l'histoire du féminisme, l'éducation des filles et la littérature féminine une remarquable anthologie d'œuvres de genres divers émanant de la plume d'une femme auteur du XviII ${ }^{\mathrm{e}}$ siècle (1711-1780), parfois critiquée par Grimm et le clan des philosophes, mais célèbre dans toute l'Europe à son époque et au XIX $x^{e}$ siècle grâce, surtout, à son Magasin des enfants. Parmi les différents contes merveilleux qu'il contient, seul La Belle et la Bête a, de nos jours, résisté à l'oubli.

Barbara Kaltz, auteur d'un article portant sur la réception allemande de l'œuvre de Mme Leprince de Beaumont ( La Belle et la Bête - Zur Rezeption der Werke Mme Leprince de Beaumonts im deutschsprachigen Raum ", Romanistische Zeitschrift für Literaturgeschichte $13, \mathrm{n}^{\circ} 3-4,1989$ ), se propose de mieux la faire connaître, travail d'autant plus nécessaire que les encyclopédies, y compris les plus récentes, continuent de répercuter des erreurs sur la vie et l'œuvre d'un auteur laissé pour compte par la presque totalité des histoires de la littérature. Pour combler ces lacunes, B. Kaltz présente, avec ce volume, ce qu'elle appelle modestement une " première approche " de son œuvre - approche particulièrement riche, soulignons-le - et qui consacre une étape de ses recherches en cours. L'enquête, scrupuleusement menée et servie notamment par la maîtrise de la langue allemande, fait état d'une mine de documents collectés dans un nombre assez considérable de bibliothèques d'Europe et d'outreAtlantique, conformément au principe d'hétérogénéité énoncé par Jean Sgard dans son Dictionnaire des journalistes.

L'avant-propos, dans lequel ces intentions et méthodes sont développées, retrace les étapes de la vie de l'auteur. Démarche parfaitement justifiée, tant l'œuvre de Mme de Beaumont est nourrie de son expérience. Ayant renoncé au couvent où elle avait fait deux années de noviciat, elle exerça longtemps en Angleterre, puis en France, le métier 
de gouvernante auprès de jeunes filles de milieu aristocratique, contrainte qu'elle était de gagner sa vie. Elle publiait dans le même temps. Aussi avait-t-elle eu l'occasion de tester les méthodes éducatives qu'elle préconisait.

Dans une passionnante et copieuse introduction (qui occupe presque la moitié du livre), l'auteur offre un grand nombre d'informations et d'analyses sur les divers ouvrages de Mme de Beaumont. Y sont présentés, dans l'ordre chronologique, sept d'entre eux, dont l'auteur a sélectionné ensuite douze extraits.

5 La Lettre en réponse à "l'Année merveilleuse » (1748), donnée ici dans son intégralité, a été écrite par Mme de Beaumont au début de sa carrière. B. Kalz la considère comme essentielle à la compréhension de toute l'œuvre. Son auteur, réfutant la thèse soutenue en 1748 par un proche des philosophes, François Coyer, y défend l'idée d'une supériorité naturelle des femmes en bien des domaines : corps, esprit, vertu, talents d'écriture... Elle déplore que les qualités des jeunes filles soient brimées par une éducation déficiente intentionnellement destinée à les maintenir dans une ignorance presque totale. Le Nouveau magasin françois, publié en Angleterre (1750-1752) et rebaptisé ensuite le Magasin des dames, est l'un des tout premiers périodiques dirigés par une femme et destiné aux femmes. Les contributions de Mme de Beaumont y furent diverses et variées : pour l'œuvre proprement littéraire, il s'agit de contes (moraux, essentiellement), de fables, de poésies et de nombreuses lettres, auxquelles elle ajoutait des articles de critique littéraire et de vulgarisation scientifique, à côté de ceux fournis par d'éminents savants. B. Kaltz souligne la faible contribution féminine au périodique, auquel collaborèrent Fontenelle, Voltaire, Piron et Marmontel. La Force du génie naturel. Histoire de Molly, paysanne poëte (juillet 1751), retenu ici, est un conte qui accuse la tyrannie des parents et l'anéantissement des talents féminins par la société, jugée criminelle à cet égard.

6 L'Education complette, ou Abrégé d'histoire universelle (1752-1753) est destiné aux gouvernantes et l'auteur y expose les méthodes qu'elle a expérimentées. Elle y reprend, en condensé, L'Histoire ancienne de Charles Rollin, sous la forme de questions-réponses que les élèves doivent apprendre, avant d'entendre les explications et commentaires du maître, ainsi qu'un «trait d'histoire » raconté pour terminer la leçon. Ont été retenus pour l'anthologie l'avertissement et la préface. Son auteur y défend la nécessité d'une vocation pédagogique et l'emploi de méthodes individualisées. Les défauts de l'éducation particulière en Angleterre sont passés en revue et des conseils sont prodigués en direction des parents et des maîtres.

7 Du Magasin des enfans (1756), B. Kaltz a dénombré 130 éditions françaises sur les trente années qui ont suivi sa publication. Elle expose les remaniements successifs apportés au texte, au XIX ${ }^{\text {e }}$, dans un souci d'adaptation linguistique et de mise à jour scientifique. Elle souligne l'originalité de l'approche pédagogique de Mme de Beaumont, qui entend délivrer une éducation morale et religieuse de manière plaisante et divertissante, et milite pour que les filles ne soient pas écartées de l'enseignement des sciences. Les méthodes éducatives qui y sont mises en application s'appuient sur le dialogue entre le maitre et ses élèves. L'auteur estime nécessaire d'en appeler très tôt à la raison de l'enfant et invite les pédagogues à utiliser ses leçons en les adaptant. Le Magasin est l'un des premiers livres destinés à l'éducation des filles, à côté du Télémaque, pour les garçons, et servit à l'enseignement du français à l'étranger. Aux leçons s'ajoutent des histoires, fables et contes merveilleux qui connurent de nombreuses rééditions séparées aux XVIII ${ }^{\mathrm{e}}$ et XIX ${ }^{\mathrm{e}}$. Parfois, furent introduits dans l'ouvrage des contes écrits par 
les précurseurs du genre. Ont été retenus pour l'anthologie la Fable de la veuve et de ses deux filles, largement inspirée des Fées de Perrault, et le célèbre conte de La Belle et la Bête. Le dialogue qui leur fait suite a été écarté, mais il est résumé dans l'introduction, où ces textes sont comparés à leurs sources (notamment le conte de Mme de Villeneuve). L'auteur renvoyant aux articles et ouvrages anglais et allemands (Stewart, Hearne, Zipes) qui ont étudié les influences de La Belle et la Bête sur la littérature, on peut s'étonner qu'elle ne mentionne pas le livre de Marina Warner, From the Blonde to the Beast, également absent de l'importante bibliographie finale. Enfin, les adaptations du conte à la scène et au cinéma sont passées en revue.

8 Le Magasin des adolescentes (1760) constitue une suite du précédent, qui rencontra un peu moins de succès en Europe, même si elle fut utilisée pour l'éducation des demoiselles (et parfois lue par les garçons). Trois extraits sont donnés : l'avertissement et deux dialogues, qui fournissent une illustration aux principes pédagogiques développés dans la première sous forme théorique. On y attire l'attention des mères (souvent condamnées pour leurs négligences) sur le choix des gouvernantes. On fait reposer l'enseignement sur l'Évangile, tout en insistant, ici comme ailleurs, sur l'importance de la raison dans la formation de l'esprit et du cœur. On propose même que soit ajouté l'enseignement du latin à la diversité des matières que les filles doivent étudier, de sorte qu'elles puissent suivre plus tard l'éducation de leurs enfants (ce qui à l'époque, est tout à fait novateur).

9 Le Mentor moderne (1772-1773) est destiné à l'enseignement des garçons. L'influence de Fénelon y est évidemment perceptible, même si l'auteur cherche à s'en démarquer dans un dernier volume à l'usage des maîtres. Le livre, organisé en journées lui aussi, se fonde sur les mêmes principes que les précédents, mais n'offre pas le même contenu. En sont exclus les contes de fées, les anecdotes et les histoires, réservés aux filles. L'histoire ancienne et la géographie y occupent une place considérable, à côté du latin, de la mythologie. Les extraits sélectionnés sont l'épître dédicatoire, l'avertissement et un extrait de la conclusion.

On ne s'étonnera pas que Mme de Beaumont se soit adonnée au genre lancé par Marmontel. Trois contes forment le recueil des Contes moraux (1773), suivis des Nouveaux contes moraux (1776). Dans la préface du premier recueil, retenue pour l'anthologie, elle répond aux accusations portées contre son style et la tendance moralisatrice de ses œuvres, tout en soutenant la thèse de l'utilité des romans pour la formation morale des filles. L'Histoire de Céleste, du même recueil, est donnée à lire, les deux autres sont résumés. L'ensemble est une illustration de la bataille menée par l'auteur, tout au long de sa carrière, pour faire évoluer la condition féminine par le levier de l'éducation.

11 Cette synthèse bien conduite, servie par une érudition jamais pesante et écrite dans style vivant, a, parmi d'autres mérites, celui de souligner les liens entre les différents extraits et de montrer à la fois la diversité et l'unité d'une œuvre. Barbara Kaltz la replace par rapport à ses prédécesseurs et successeurs pour en souligner les enjeux et le rayonnement. Accordant une grande place à la réception européenne, elle dénombre les éditions, traductions et rééditions (rectifiant les erreurs des dictionnaires), donne des indications sur les collections des bibliothèques, fait état des critiques de l'époque. Un tel travail marque une avancée notable dans la recherche sur Mme de Beaumont et les domaines que couvrent ses productions. Une présentation aussi approfondie de ces morceaux choisis ne peut qu'attiser la curiosité du lecteur à l'égard des textes 
intégraux et fournit une base de données fort appréciable pour ceux qui s'intéressent à cet auteur méconnu. 